\title{
Pam2CSK4 (TLR2 agonist) induces periodontal destruction in mice
}

\section{João Antonio Chaves de SOUZA $^{(a)}$ iD \\ Fernando Augusto Cintra MAGALHÃES(b)}

Guilherme Jose Pimentel Lopes de OLIVEIRA(c) iD

Rafael Scaf DE MOLON(d)

José Antonio ZUANON(e)

Pedro Paulo Chaves de SOUZA ${ }^{(f)}$

(a) Universidade Federal de Goiás - UFG, School of Dentistry, Department of Periodontology, Goiania, GO, Brazil.

(b) Universidade Federal do Maranhão - UFMA, Department of Nursing, Imperatriz, MA, Brazil.

(c) Universidade Federal de Uberlândia UFU, School of Dentistry, Department of Periodontology, Uberlândia, MG, Brazil.

(d) Universidade Estadual Paulista - Unesp, School of Dentistry, Department of Diagnosis and Surgery, Araraquara, SP, Brazil.

(e) Universidade Estadual Paulista - Unesp, School of Dentistry, Department of Physiology and Pathology, Araraquara, SP, Brazil.

(f) Universidade Federal de Goiás - UFG, School of Dentistry, Department of Stomatology, Goiania, GO, Brazil.

Declaration of Interests: The authors certify that they have no commercial or associative interest that represents a conflict of interest in connection with the manuscript.

\section{Corresponding Author:}

Pedro Paulo Chaves de Souza

E-mail: pedrosouza@ufg.br

https://doi.org/10.1590/1807-3107bor-2020.vol34.0012

Submitted: May 19, 2019

Accepted for publication: December 10, 2019

Last revision: January 13, 2020
Abstract: Lipoproteins are important bacterial immunostimulating molecules capable of inducing receptor activator of nuclear factor- $\kappa \mathrm{B}$ (RANKL) and osteoclast formation in vitro and in vivo. Although these molecules are present in periodontopathogenic bacteria, their role in periodontitis is not known. In this study, we used $\mathrm{Pam}_{2} \mathrm{CSK}_{4}$ (PAM2), a synthetic molecule that mimics bacterial lipoprotein, to investigate the effects of lipoproteins on periodontitis in mice. C57BL/6 male mice were randomly divided into three experimental groups: 1) Negative control group: animals received vehicle injection; 2) Positive control group: animals received injection of Escherichia coli lipopolysaccharide (LPS); 3) PAM2 group: animals received PAM2 injection. All the injections were performed bilaterally every other day into the palatal mucosa between first and second molars. After twenty-four days, the animals were euthanized to assess alveolar bone volume (micro-CT), cellular and extracellular composition in the gingiva (stereometric analysis), and osteoclast numbers (TRAP staining). Treatment with either PAM2 or LPS induced gingival inflammation, as demonstrated by increased infiltration of inflammatory cells and enhanced angiogenesis, associated with a smaller number of fibroblasts and decreased extracellular matrix. Importantly, treatment not only with LPS but also with PAM2 resulted in a larger number of TRAP+ multinucleated osteoclasts and significant loss of alveolar bone. Collectively, our data demonstrate that PAM2 can induce gingival inflammation and bone loss in mice, broadening the avenues of investigation into the role of lipoproteins in the pathogenesis of periodontal disease.

Keywords: Bone and Bones; Inflammation; Lipoproteins; Toll-Like Receptors; Mice; Periodontal Diseases; Osteogenesis.

\section{Introduction}

Periodontitis is a polymicrobial disease characterized by the host inflammation-dependent destruction of periodontal structures, leading to long-term alveolar bone loss and loosening of teeth. ${ }^{1}$ The host response is initiated by the recognition of pathogen-associated molecular patterns (PAMPs), such as the lipoproteins and lipopolysaccharides (LPS) present in Gram-negative bacteria. ${ }^{2,3}$ The immune system recognizes and responds to the PAMPs through different pathogen recognition receptors (PRRs) such as Toll-like receptors (TLRs), leading to up-regulation of a wide variety 
of inflammatory mediators, and to a consequential antimicrobial response. ${ }^{4,5,6,7}$ Recent findings in mouse models point out the possible transfer of a dysbiotic oral microbiome across individuals and generations, thereby highlighting the importance of identifying bacterial signatures and host receptors that could contribute to the pathogenesis of periodontitis. ${ }^{8}$

Animal models have been used to help understand the mechanisms involved in the pathogenesis of periodontitis, and provide important information on the inflammatory response associated with host-microbial interactions. ${ }^{9,10,11,12,13,14,15,16,17}$ The main advantage of experimental models is that they allow the specific mechanisms involved in the pathogenesis of periodontitis to be studied in a more targeted and controlled manner. ${ }^{10,11}$ The possibility of genetic modifications makes mice an excellent model to study the host response in periodontitis, and enables a better understanding of the role of different proteins and receptors in the recognition of microbes. ${ }^{9}$ On the other hand, the use of genetically modified bacteria and purified bacterial molecules helps us understand the role of specific PAMPs in the initiation of an immune response., ${ }^{9,18,19}$

Its ubiquitous presence in Gram-negative bacteria makes LPS the most widely studied PAMP, and several studies show the importance of LPS-induced activation of TLR4 for periodontal breakdown., ${ }^{9,12,20}$ Many bacteria also contain lipoproteins as important virulence factors, caused by their strong immunostimulatory activity. ${ }^{21}$ Porphyromonas gingivalis (P. gingivalis) is recognized as an important pathogenic bacterium in human periodontitis. These bacteria induce gingival inflammation and periodontal breakdown by activation of TLR2 in experimental models of periodontitis in mice. ${ }^{22}$ However, the bacterial components isolated from $P$. gingivalis are not the ideal tools to study TLR2-dependent periodontitis, since $P$. gingivalis LPS may present large variations among companies and batches, because this bacteria is able to modify its PAMPs in order to escape the immune system. ${ }^{1,23,24}$

The synthetic lipopeptide $\mathrm{Pam}_{2} \mathrm{CSK}_{4}$ (PAM2) mimics bacterial lipoprotein and binds specifically to TLR2, preferentially to the TLR2/6 heterodimer. ${ }^{25}$ Previous reports demonstrated that PAM2 is capable of inducing bone resorption through osteoclast activation. The mechanisms by which PAM 2 induces osteoclastogenesis involve both direct stimulation of osteoclast precursors and product ${ }^{22,26}$ In an effort to understand how TLR2 induces periodontitis, the authors compared the effect of PAM2 with that of a well-characterized Escherichia coli LPS., ${ }^{90,12}$

\section{Methodology}

\section{Animal care}

Mice and surgical procedures were handled according to the guidelines of the local Ethical Committee for Animal Care and Use (CEUA \#11/2015). The animals were kept on the animal facilities of the São Paulo State University (UNESP), School of Dentistry, Araraquara, (Araraquara, Sao Paulo, Brazil), at a controlled temperature $\left(23^{\circ} \mathrm{C} \pm 2^{\circ} \mathrm{C}\right)$ and a 12-hour light/dark cycle. Mice were housed in plastic cages, fed a standard laboratory diet, and given water ad libitum.

\section{LPS and PAM2 Injection Model}

A total of twenty-one 10-week-old C57BL/6 male mice with an average weight of $25 \mathrm{~g}$ were used in this study. The animals were sedated with isoflurane (Cristália, Itapira, Brazil), and received $3-\mu \mathrm{L}$ local injections using custom-designed 0.375 -inch $\times 12$-gauge needles attached to a $10-\mu \mathrm{L}$ syringe (Hamilton Company, Reno, USA). The injections were administered into the palatal mucosa between the first and second maxillary molars, and the animals were randomly divided to receive the following substances: a) Negative control group (CTR): phosphate-buffered saline (PBS); b) Positive control group (LPS): $5 \mu$ g of E. coli LPS (Lipopolysaccharide from Escherichia coli 0127:B8; Sigma Aldrich, St. Louis, USA); c) Experimental PAM2 group (PAM2): $5 \mu$ g of $\mathrm{Pam}_{2} \mathrm{CSK}_{4}$ (InvivoGen, San Diego, USA; synthetic diacylated lipoprotein TLR2/TLR6 ligand). All the injections were given three times a week for 24 days.

At the end of the experimental period, the animals were euthanized, and their maxillae were fixed in $4 \%$ paraformaldehyde for 24 hours, and stored in $70 \%$ ethanol to perform the analyses described below. 


\section{Micro-computed tomography scanning ( $\mu$ CT scanning)}

Bone samples were carefully harvested to evaluate bone destruction after periodontal disease induction. Previously, the maxillae were washed in distilled water, and wrapped in moist paper to prevent artefacts caused by dehydration during the scanning process. A high-resolution micro-CT imaging system $(\mu \mathrm{CT}$ Skyscan 1176; Skyscan, Kontich, Belgium) was used with the following parameters: $18 \mu \mathrm{m}$ isotropic space resolution, X-ray generator at $57 \mathrm{kVp}$, beam current at $184 \mu \mathrm{A}$, and $0.5 \mathrm{~mm}$ aluminum filter. The following parameters were applied to reconstruct the samples using an appropriate software program (NRecon, v.1.6.1.5, Skyscan, Kontich, Belgium): defect-pixel masking: $10 \%$; beam hardening: $20 \%$; smoothing: 1 ; and individually calculated misalignment compensation values. The images were imported into specific software (Data Viewer, v.1.4.3.1, Skyscan, Kontich, Belgium) to generate multiplanar reconstructed images, and coronal datasets were saved for further volumetric analysis. Bone volume fraction (BV/TV) analysis was assessed using appropriate software (CT-Analyser software v1.10.1.0; Skyscan, Kontich, Belgium), as previously described. ${ }^{27,28}$ Briefly, a region of interested (ROI) with a cone frustum shape was manually delimitated, and 70 consecutive coronal slices were measured with a ROI extending from the root apices to the alveolar bone crest (ABC), and from the mesial root of the first molar to the distal root of the third molar, including the trabecular bone of the maxillae alveolar ridge, and excluding the periodontal ligament and teeth roots. Scans were de-identified and periodontal bone loss was measured by a blinded and experienced examiner (FACM).

\section{Stereometric analysis}

After scanning, the same samples were decalcified in ethylenediaminetetraacetic acid (EDTA) $(0.5 \mathrm{M}, \mathrm{pH}$ 8.0) for 4 weeks at room temperature, and embedded in paraffin. Seven hemi-maxillae per group were used to evaluate morphologic changes. Serial parasagittal sections $(5 \mu \mathrm{m})$ were obtained on the buccal-palatal plane (transversal), mounted on slides and stained with hematoxylin \& eosin. Two sections of each tooth were selected for stereometric analyses. Images were captured using a digital camera (Leica DFC 300, Leica - Reichert Diastar Products \& Jung, Wetzlar, Germany) coupled to an optical microscope (Leica DMLS, Leica - Reichert Diastar Products \& Jung, Wetzlar, Germany) set at 200x magnification. A $17,765 \mu \mathrm{m}^{2}$ grid with $9 \times 430-\mu \mathrm{m}$ squares (in scale with the 40x magnification used in all the images) was constructed using image editing software(Adobe Photoshop CS6, Adobe System Incorporated, San Jose, USA) and overlaid on the digital images as described elsewhere. ${ }^{29}$ The ROI was delimitated by the whole grid, which was positioned on the connective tissue, associated with the supra-crestal area at the palatal bone. A blinded and calibrated examiner (GJPLO) performed the stereometric analysis using a point-counting technique in a two-dimensional plane of the grid, to match the tissue components with the points of intersection. Cell type identification (inflammatory or fibroblast) was based on the morphological characteristics of the cell. Inflammatory cells usually have a rounded shape, whereas fibroblasts are elongated/fusiform. Although not all elongated cells are defined as fibroblasts, the authors of the present study called this type of cell as non-inflammatory. Blood vessels and other structures (called the extracellular matrix) were quantified, as described elsewhere. 29,30,31 The structures were evaluated using a light microscope at a higher magnification to ensure accurate recognition, and thus resolve any doubt by the investigator. If any doubt remained, the structure was recorded as 'extracellular matrix.' The presence of each structure was expressed as a percentage of the total points analyzed in the total area, as previously described. ${ }^{29}$

\section{TRAP staining}

Sections were stained using a TRAP staining kit (Leukocyte Acid Phosphatase 387-A, Sigma-Aldrich, St. Louis, USA) to identify the presence of osteoclast. Sections were deparaffinized and rehydrated, fixed in a fixative solution for 30 seconds, and then incubated at $37^{\circ} \mathrm{C}$ in TRAP staining solution (containing diazotized fast garnet, naphthol AS-BI phosphate, acetate, and tartrate solution) for 60 minutes, as described elsewhere. ${ }^{32,33}$ After counterstaining with Harris hematoxylin, sections were dehydrated 
and cover-slipped. The total number of TRAP+ multinucleated cells containing 2 or more nuclei was counted in the palatal and buccal side of the maxilla, in a total area of $245,877 \mu \mathrm{m}^{2}$. Analysis was performed on a total of 7 mice per group, by a blinded and experienced examiner (R.S.M.).

\section{Statistics}

Analyses were performed using GraphPad Prism Software (Graph-Pad Prism Software, La Jolla, USA). Group measurements were expressed as mean \pm the standard error of the mean (SEM). The Shapiro-Wilk test confirmed the normal distribution of all data $(p>0.05)$. Statistical significance was assessed using one-way analysis of variance (ANOVA) followed by post hoc Tukey's test for multiple comparisons among groups. Differences were considered significant at $p<0.05$.

\section{Results}

\section{PAM2-induced gingival inflammation decreases alveolar bone mass}

The general effects of the LPS and thePAM2 injections in the palatal aspect of the maxilla were evaluated by measuring the BV/TV of the alveolar ridge. The
micro-CT analysis revealed that the alveolar bone architecture in the CTR group was maintained (Figures 1A and 1D). Alveolar bone resorption was seen in the LPS and PAM2 injection groups, and was statistically higher compared to that of the CTR group $(p<0.0001)$ (Figures 1B, 1C and 1D). The LPS group was characterized by more severe alveolar bone resorption than the PAM2 group $(p<0.05)$ (Figure 1D).

\section{PAM2 induces gingival inflammation and breakdown of the extracellular matrix}

Histologic stereometric analysis of the maxillae was performed to assess the effects on the cellular and extracellular matrix composition (Figures 2A-C1 and Figures 2D-G). PAM2 treatment resulted in a greater proportion of inflammatory cells in PAM2 (39.62 $\pm 2.45 \%)$, compared to the vehicle-treated controls $(\mathrm{p}<0.0001)$ $(11.14 \pm 8.98 \%)$. The treatment also enhanced the proportion of vascular structures $(\mathrm{p}<0.05)$ $(14.47 \pm 5.46 \%)$, compared with the vehicle-treated controls $(10.66 \pm 2.93 \%)$. The inflammatory response was associated with a smaller number of gingival non-inflammatory cells $(p<0.0001)(5.71 \pm 3.26 \%)$ (Figures 2A-C1 and Figures 2D-E), compared with the controls $(24.38 \pm 4.30 \%)$, and decreased extracellular
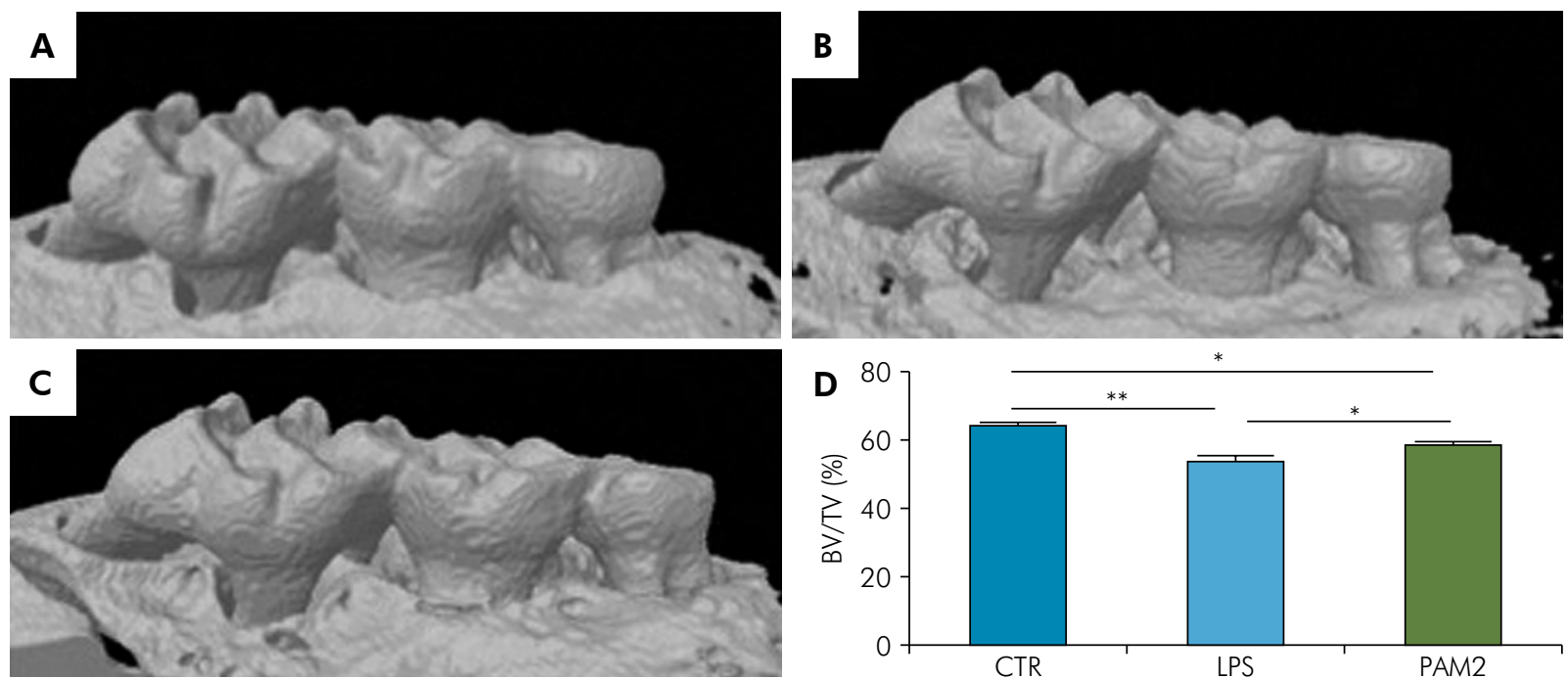

*Statistically significant difference from the indicated group $\mathrm{p}<0.05 ;{ }^{* *}$ Statistically significant difference from the indicated group $\mathrm{p}<0.0001$. Differences among groups were calculated by one-way ANOVA followed by Tukey's test. Data represent the mean \pm SEM.

Figure 1. Microtomographic analysis of alveolar bone. (A-C): CTR group injected with saline solution ( $\mathrm{n}=7$ ); LPS group injected with $5 \mu \mathrm{g}$ LPS $(n=7)$; and PAM2 group injected with $5 \mu \mathrm{g}$ PAM2 $(n=7)$ three times a week, for 24 days, in the gingival papilla in the palatal aspect, between the first and second molars, respectively; (D): Quantification of BV/TV in the maxilla of all mice. 
matrix ( $\mathrm{p}<0.0001)(41.52 \pm 5.37 \%)$, compared with the controls $(56.24 \pm 4.66 \%)$. Similar observations were made in mice treated with LPS.

\section{PAM2 stimulates osteoclast formation}

The effect of PAM2 on osteoclast numbers was determined using TRAP staining of histological sections to investigate if the decrease in bone mass induced by PAM2 was due to increased bone resorption (Figures 3A1-C3 and 3D). PAM2 treatment resulted in a significant increase in the number of TRAP+ multinucleated cells attached to the bone surface, with extended bone contact surface, compared with the vehicle-treated control group $(p<0.001)$ (Figure 3D). As expected, LPS treatment was also associated with a larger number of TRAP+ multinucleated osteoclasts $(\mathrm{p}<0.0001)$.

\section{Discussion}

Several bacterial components and cellular pathways are involved in the pathogenesis of periodontitis. For this reason, there is no complete animal model that embraces all aspects of the disease in humans. Different
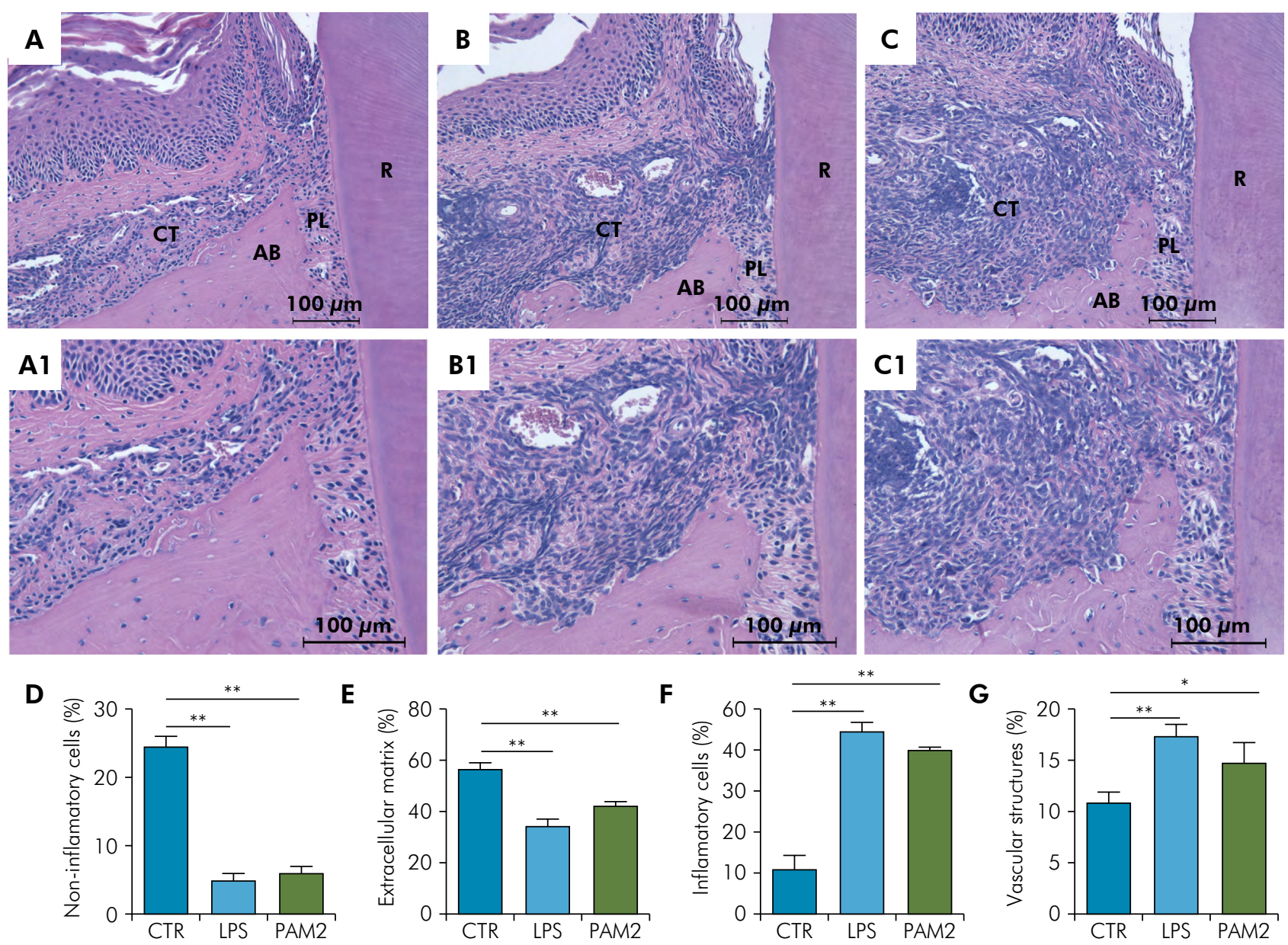

AB: alveolar bone; $C T$ : connective tissue; PL: periodontal ligament; R: root. *Statistically significant different from the indicated group $p<0.05$; **Statistically significant difference from the indicated group $\mathrm{p}<0.0001$. Differences among the groups were calculated by one-way ANOVA followed by Tukey's test. Data represent the mean \pm SEM.

Figure 2. Representative H\&E-stained images from the maxilla, and quantification of stereometric findings: (A-C): CTR ( $\mathrm{n}=7$ ), LPS $(n=7)$ and PAM2 ( $n=7)$ groups, respectively. Original magnification, 200x. (A1-C1) CTR, LPS and PAM2 groups, respectively. Original magnification, 400x. (D-G): Quantification of relative presence of fibroblasts, extracellular matrix, inflammatory cells, and vascular structures. 

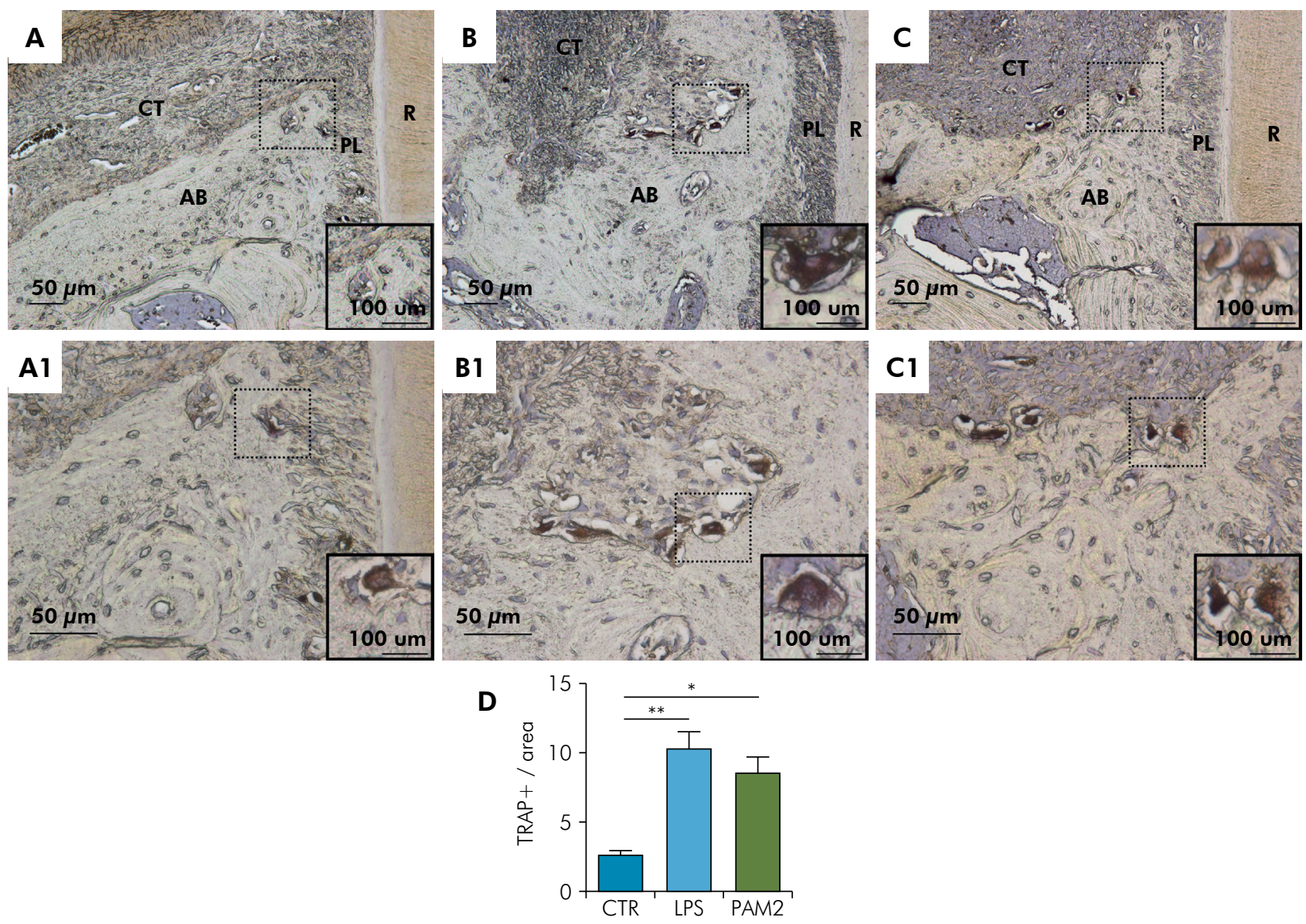

AB: alveolar bone; CT: connective tissue; PL: periodontal ligament; R: root. *Statistically significant difference from indicated groups, $p<0.001$. **Statistically significant difference from indicated groups, $p<0.0001$. Differences among groups were calculated by one-way ANOVA followed by Tukey's test. Data represent the mean \pm SEM.

Figure 3. Counting of TRAP+ multinucleated cells. $(A-C)$ : Control $(n=7)$, LPS $(n=7)$ and PAM $(n=7)$ groups respectively. Original magnification, 20x. (A1-C1): Magnified views of the control, LPS and PAM groups. Original magnification, 40x. Insets are magnified views of individual TRAP+ cells in all groups; (D): Quantification of TRAP+ cell number in all mice and groups ( $n=7$ mice per group).

methods have been used to induce periodontitis in rodents, including gavage, bacterial infection, ligature and LPS injections. ${ }^{10,13,4,17,29,34,35}$ The selection of a specific model depends on the aspects of the disease that will be focused on. ${ }^{9}$ Each model can mimic some components of the pathological process during the course of periodontal disease. By selecting the appropriate model to test a specific hypothesis, each component can be investigated individually. ${ }^{9}$ In studying the complex aspects involved in the pathogenesis of periodontitis, the animal models offer a vast field for exploration, by promoting a better understanding of the interaction between different bacterial components and the periodontal tissues of the host. ${ }^{10,11,36}$
A localized injection of bacteria or pathogenic component directly into the palatal gingival tissue is a widely used model to study periodontal disease. ${ }^{37,38}$ This method causes significant periodontal inflammation, leading to the expression of a large number of inflammatory mediators that lead to bone loss near the area of the injection..$^{39,40}$ Furthermore, the injection of synthetic components allows control of the stimulus intensity, the vehicle selection and the substance volume, independent of variables such as colonization and survival of exogenous bacteria. The origin of the bacterial component used is the main variable to be considered, since different PAMPs activate different TLRs. Among these 
receptors, TLR4 recognizes lipid A in LPS, whereas TLR2 recognizes several microbial components, including lipoteichoic acid, peptidoglycans, and lipoproteins. ${ }^{4}$ TLR activation triggers the production of inflammatory cytokines by activating several signaling pathways, including MAPK and NF- $\mathrm{B}$, leading to inflammatory response and bone resorption. ${ }^{27,41,42,43}$

The characterization of lipoproteins as potent inducers of bone resorption ${ }^{25}$ and the identification of these molecules as constituents of periodontopathogenic bacteria ${ }^{19,22,26}$ led us to investigate the ability of PAM2 to induce periodontal disease. In the present study, the authors demonstrated that PAM2 is as potent as LPS in inducing inflammation and periodontal bone loss in mice.

Our data corroborate those of previous studies reporting the ability of periodontopathogenic bacteria to induce alveolar bone loss by activating TLR2 ${ }^{18,44}$ Interestingly, TLR2 ${ }^{--}$are more effective in bacterial clearance, and are protected from periodontal bone loss induced by $P$. gingivalis. ${ }^{44}$ Further evidencing the importance of TLR2 for periodontal disease, TLR2 deficient mice are protected from alveolar bone destruction caused by Tannerella forsy thia.$^{45}$ Although the previous data clearly demonstrate the importance of TLR2 in the pathogenesis of periodontal bone loss, the direct stimulation of periodontal disease using lipoprotein, to the best of our knowledge, has not yet been previously reported.

In the present study we choose to use a TLR4 agonist (Escherichia coli LPS) as a positive control instead of using a periodontopathogenic bacteria such as $P$. gingivalis, Tannerella forsythia or Treponema denticola. These common periodontopathogenic bacteria species, referred to as the "red complex," and closely related to periodontal disease, are known to induce bone resorption by activating the TLR2. This was the reason why LPS derived from E. coli (a non-periodontopathogenic species) was used as a positive control, namely, because it stimulates TLR4. Furthermore, LPS from Escherichia coli usually leads to an intense inflammatory process in the connective tissue and to bone resorption, each of which plays an important role as a positive control. The literature reports that both TLR2 and TLR4 are expressed by bone cells, and once these receptors are activated by their ligands, namely lipoproteins and LPS, they can stimulate bone loss, during the course of inflammatory processes. ${ }^{3,22,42,43}$ We found that both molecules could promote well-located inflammatory bone loss by micro-CT and histological analyses. Compared with the negative control group, both LPS and PAM2 groups demonstrated a similar potential for periodontal disease induction. These findings corroborate previous findings showing osteoclast differentiation leading to severe bone loss in vivo when PAM2 was injected in mice. ${ }^{22,26}$

In our study, intense inflammation and alveolar bone loss in the periodontal tissue of animals stimulated with Escherichia coli LPS and PAM2 showed the potential involvement of both TLR2 and TLR4 in both the inflammation induction and the progression of periodontitis. As expected, these features were not evidenced in the CTR group, which was characterized by absence of tissue inflammation and bone resorption. Furthermore, the number of TRAP+ cells observed in the PAM2 group confirms the participation of TLR2 in in vivo osteoclastogenesis, which might explain the greater bone resorption in the animals receiving PAM2 injections. The similarity in the radiographic and histological characteristics of LPS and PAM2 closely resembles the features of human periodontitis, validating this approach as one that captures the essential ${ }^{46,47}$

\section{Conclusion}

Our findings indicate that continued injections of PAM2 into the palatal mucosa were an effective and reproducible model to induce gingival inflammation and alveolar bone loss in mice. This model can provide a new tool to investigate the specific role of TLR2 during the course of periodontal disease, considering that these mechanisms are not yet completely understood.

\section{Acknowledgment}

Support was provided by Grant \#080/2012, awarded by Science Without Borders to P.P.C.S. and Fundação de Amparo à Pesquisa do Estado de São Paulo (FAPESP) \#2014/05283-3. R.S.M. is currently supported by a grant provided by FAPESP \#2015/21697-5. 


\section{References}

1. Tonetti MS, Greenwell H, Kornman KS. Staging and grading of periodontitis: Framework and proposal of a new classification and case definition. J Clin Periodontol. 2018;45 Suppl 20S149-S61. https://doi.org/10.1111/icpe.12945

2. Holden JA, Attard TJ, Laughton KM, Mansell A, O’Brien-Simpson NM, Reynolds EC. Porphyromonas gingivalis lipopolysaccharide weakly activates M1 and M2 polarized mouse macrophages but induces inflammatory cytokines. Infect Immun. 2014 Oct;82(10):4190-203. https://doi.org/10.1128/IAI.02325-14

3. Nakamura H, Fukusaki Y, Yoshimura A, Shiraishi C, Kishimoto M, Kaneko T, et al. Lack of Toll-like receptor 4 decreases lipopolysaccharide-induced bone resorption in C3H/HeJ mice in vivo. Oral Microbiol Immunol. 2008 Jun;23(3):190-5. https://doi.org/10.1111/j.1399-302X.2007.00410.x

4. Kawai T, Akira S. The role of pattern-recognition receptors in innate immunity: update on Toll-like receptors. Nat Immunol. 2010 May; 11(5):373-84. https://doi.org/10.1038/ni.1863

5. Lin J, Bi L, Yu X, Kawai T, Taubman MA, Shen B, et al. Porphyromonas gingivalis exacerbates ligature-induced, RANKL-dependent alveolar bone resorption via differential regulation of Toll-like receptor 2 (TLR2) and TLR4. Infect Immun. 2014 Oct;82(10):4127-34. https://doi.org/10.1128/IAI.02084-14

6. Maekawa T, Krauss JL, Abe T, Jotwani R, Triantafilou M, Triantafilou K, et al. Porphyromonas gingivalis manipulates complement and TLR signaling to uncouple bacterial clearance from inflammation and promote dysbiosis. Cell Host Microbe. 2014 Jun;15(6):768-78. https://doi.org/10.1016/i.chom.2014.05.012

7. Palm E, Demirel I, Bengtsson T, Khalaf H. The role of toll-like and protease-activated receptors in the expression of cytokines by gingival fibroblasts stimulated with the periodontal pathogen Porphyromonas gingivalis. Cytokine. 2015 Dec;76(2):424-32. https://doi.org/10.1016/i.cyto.2015.08.263

8. Payne MA, Hashim A, Alsam A, Joseph S, Aduse-Opoku J, Wade W, et al. Horizontal and Vertical Transfer of Oral Microbial Dysbiosis and Periodontal Disease. J Dent Res. 2019 Dec;98(13):1503-10.https://doi.org/10.1177/0022034519877150

9. Graves DT, Kang J, Andriankaja O, Wada K, Rossa C Jr. Animal models to study host-bacteria interactions involved in periodontitis. Front Oral Biol. 2012;15:117-32. https://doi.org/10.1159/000329675

10. Molon RS, Avila ED, Nogueira AVB, Souza JAC, Avila-Campos MJ, Andrade CR, et al. Evaluation of the host response in various models of induced periodontal disease in mice. J Periodontol. 2014 Mar;85(3):465-77. https://doi.org/10.1902/jop.2013.130225

11. Polak D, Wilensky A, Shapira L, Halabi A, Goldstein D, Weiss El, et al. Mouse model of experimental periodontitis induced by Porphyromonas gingivalis/Fusobacterium nucleatum infection: bone loss and host response. J Clin Periodontol. 2009 May;36(5):406-10. https://doi.org/10.1111/j.1600-051X.2009.01393.x

12. Graves DT, Fine D, Teng YT, Van Dyke TE, Hajishengallis G. The use of rodent models to investigate host-bacteria interactions related to periodontal diseases. J Clin Periodontol. 2008 Feb;35(2):89-105. https://doi.org/10.1111/j.1600-051X.2007.01172.x

13. de Molon RS, de Avila ED, Cirelli JA. Host responses induced by different animal models of periodontal disease: a literature review. J Investig Clin Dent. 2013 Nov;4(4):211-8. https://doi.org/10.1111/jicd.12018

14. Molon RS, Mascarenhas VI, Avila ED, Finoti LS, Toffoli GB, Spolidorio DM, et al. Long-term evaluation of oral gavage with periodontopathogens or ligature induction of experimental periodontal disease in mice. Clin Oral Investig. 2016 Jul;20(6):1203-16. https://doi.org/10.1007/s00784-015-1607-0

15. Molon RS, Park CH, Jin Q, Sugai J, Cirelli JA. Characterization of ligature-induced experimental periodontitis. Microsc Res Tech. 2018 Dec;81(12):1412-21. https://doi.org/10.1002/jemt.23101

16. Macari S, Madeira MF, Lima IL, Pereira TS, Dias GJ, Cirelli JA, et al. ST2 regulates bone loss in a site-dependent and estrogen-dependent manner. J Cell Biochem. 2018 Nov; 19(10):8511-21. https://doi.org/10.1002/jcb.27080

17. Cavagni J, Macedo IC, Gaio EJ, Souza A, Molon RS, Cirelli JA, et al. Obesity and hyperlipidemia modulate alveolar bone loss in wistar rats. J Periodontol. 2016 Feb;87(2):e9-17. https://doi.org/10.1902/jop.2015.150330

18. Darveau RP, Pham TT, Lemley K, Reife RA, Bainbridge BW, Coats SR, et al. Porphyromonas gingivalis lipopolysaccharide contains multiple lipid A species that functionally interact with both toll-like receptors 2 and 4. Infect Immun. 2004 Sep;72(9):5041-51. https://doi.org/10.1128/IAI.72.9.5041-5051.2004

19. Jain S, Coats SR, Chang AM, Darveau RP. A novel class of lipoprotein lipase-sensitive molecules mediates Toll-like receptor 2 activation by Porphyromonas gingivalis. Infect Immun. 2013 Apr;81(4):1277-86. https://doi.org/10.1128/IAI.01036-12

20. Struillou X, Boutigny H, Soveidan A. Experimental animal models in periodontology: a review. Open Dent J. 2010;4:37-47. https://doi.org/10.2174/1874210601004010037

21. Hashimoto M, Tawaratsumida K, Kariya H, Kiyohara A, Suda Y, Krikae F, et al. Not lipoteichoic acid but lipoproteins appear to be the dominant immunobiologically active compounds in Staphylococcus aureus. J Immunol. 2006 Sep;177(5):3162-9. https://doi.org/10.4049/jimmunol.177.5.3162 
22. Kassem A, Henning P, Lundberg P, Souza PP, Lindholm C, Lerner UH. Porphyromonas gingivalis Stimulates Bone Resorption by Enhancing RANKL (Receptor Activator of NF-KB Ligand) through Activation of Toll-like Receptor 2 in Osteoblasts. J Biol Chem. 2015 Aug;290(33):20147-58. https://doi.org/10.1074/ibc.M115.655787

23. Progulske-Fox A. The Importance of Being an Antagonist as Well as Persistent. J Bacteriol. 2019 May;201(11):e00146-19. https://doi.org/10.1128/JB.00146-19

24. Slocum C, Coats SR, Hua N, Kramer C, Papadopoulos G, Weinberg EO, et al. Distinct lipid a moieties contribute to pathogen-induced site-specific vascular inflammation. PLoS Pathog. 2014 Jul;10(7):e1004215. https://doi.org/10.1371/journal.ppat.1004215

25. Buwitt-Beckmann U, Heine H, Wiesmüller KH, Jung G, Brock R, Akira S, et al. Toll-like receptor 6-independent signaling by diacylated lipopeptides. Eur J Immunol. 2005 Jan;35(1):282-9. https://doi.org/10.1002/eji.200424955

26. Kim J, Yang J, Park OJ, Kang SS, Kim WS, Kurokawa K, et al. Lipoproteins are an important bacterial component responsible for bone destruction through the induction of osteoclast differentiation and activation. J Bone Miner Res. 2013 Nov;28(11):2381-91. https://doi.org/10.1002/jbmr.1973

27. Molon RS, Hsu C, Bezouglaia O, Dry SM, Pirih FQ, Soundia A, et al. Rheumatoid Arthritis Exacerbates the Severity of Osteonecrosis of the Jaws (ONJ) in Mice. A Randomized, Prospective, Controlled Animal Study. J Bone Miner Res. 2016 Aug;31(8):1596-607. https://doi.org/10.1002/jbmr.2827

28. Molon RS, Shimamoto H, Bezouglaia O, Pirih FQ, Dry SM, Kostenuik P, et al. OPG-Fc but Not Zoledronic Acid Discontinuation Reverses Osteonecrosis of the Jaws (ONJ) in Mice. J Bone Miner Res. 2015 Sep;30(9):1627-40. https://doi.org/10.1002/jbmr.2490

29. Souza JA, Nogueira AV, Souza PP, Cirelli JA, Garlet GP, Rossa C Jr. Expression of suppressor of cytokine signaling 1 and 3 in ligature-induced periodontitis in rats. Arch Oral Biol. 2011 Oct;56(10):1120-8. https://doi.org/10.1016/i.archoralbio.2011.03.022

30. Aquino SG, Guimaraes MR, Stach-Machado DR, Silva JA, Spolidorio LC, Rossa C Jr. Differential regulation of MMP-13 expression in two models of experimentally induced periodontal disease in rats. Arch Oral Biol. 2009 Jul;54(7):609-17. https://doi.org/10.1016/i.archoralbio.2009.03.007 PMID:19393988

31. Nogueira AV, Molon RS, Nokhbehsaim M, Deschner J, Cirelli JA. Contribution of biomechanical forces to inflammation-induced bone resorption. J Clin Periodontol. 2017 Jan;44(1):31-41. https://doi.org/10.1111/icpe.12636

32. Molon RS, Cheong S, Bezouglaia O, Dry SM, Pirih F, Cirelli JA, et al. Spontaneous osteonecrosis of the jaws in the maxilla of mice on antiresorptive treatment: a novel ONJ mouse model. Bone. 2014 Nov;68:11-9. https://doi.org/10.1016/i.bone.2014.07.027

33. Soundia A, Hadaya D, Esfandi N, de Molon RS, Bezouglaia O, Dry SM, et al. Osteonecrosis of the jaws (ONJ) in mice after extraction of teeth with periradicular disease. Bone. 2016 Sep;90:133-41. https://doi.org/10.1016/i.bone.2016.06.011

34. Nogueira AV, Souza JA, Molon RS, Pereira ES, Aquino SG, Giannobile WV, et al. HMGB1 localization during experimental periodontitis. Mediators Inflamm. 2014;2014:816320. https://doi.org/10.1155/2014/816320

35. Belluci MM, Molon RS, Rossa Jr C, Tetradis S, Giro G, Cerri PS, et al. Severe magnesium deficiency compromises systemic bone mineral density and aggravates inflammatory bone resorption. J Nutr Biochem. 2019 Nov;77:108301. https://doi.org/10.1016/i.jnutbio.2019.108301

36. Van Dyke TE, Sheilesh D. Risk factors for periodontitis. J Int Acad Periodontol. 2005 Jan;7(1):3-7.

37. Souza JAC, Frasnelli SC, Curylofo-Zotti FA, Ávila-Campos MJ, Spolidório LC, Zamboni DS, et al. NOD1 in the modulation of host-microbe interactions and inflammatory bone resorption in the periodontal disease model. Immunology. 2016 Dec;149(4):374-85. https://doi.org/10.1111/imm.12654

38. Souza JA, Medeiros MC, Rocha FR, Aquino SG, Ávila-Campos MJ, Spolidorio LC, et al. Role of NOD2 and RIP2 in host-microbe interactions with Gram-negative bacteria: insights from the periodontal disease model. Innate Immun. 2016 Nov;22(8):598-611. https://doi.org/10.1177/1753425916666652

39. Garlet GP, Cardoso CR, Silva TA, Ferreira BR, Avila-Campos MJ, Cunha FQ, et al. Cytokine pattern determines the progression of experimental periodontal disease induced by Actinobacillus actinomycetemcomitans through the modulation of MMPs, RANKL, and their physiological inhibitors. Oral Microbiol Immunol. 2006 Feb;21(1):12-20. https://doi.org/10.1111/j.1399-302X.2005.00245.x

40. Sartori R, Li F, Kirkwood KL. MAP kinase phosphatase-1 protects against inflammatory bone loss. J Dent Res. 2009 Dec;88(12):1125-30. https://doi.org/10.1177/0022034509349306

41. Souza JAC, Nogueira AV, Souza PPS, Kim YJ, Lobo CS, Oliveira GJPL, et al. SOCS3 expression correlates with severity of inflammation, expression of proinflammatory cytokines, and activation of STAT3 and p38 MAPK in LPS-induced inflammation in vivo. Mediators Inflamm. 2013;2013:650812. https://doi.org/10.1155/2013/650812

42. Matsumoto C, Oda T, Yokoyama S, Tominari T, Hirata M, Miyaura C, et al. Toll-like receptor 2 heterodimers, TLR2/6 and TLR2/1 induce prostaglandin E production by osteoblasts, osteoclast formation and inflammatory periodontitis. Biochem Biophys Res Commun. 2012 Nov;428(1):110-5. https://doi.org/10.1016/i.bbrc.2012.10.016

43. Zhang P, Liu J, Xu Q, Harber G, Feng X, Michalek SM, et al. TLR2-dependent modulation of osteoclastogenesis by Porphyromonas gingivalis through differential induction of NFATcl and NF-kappaB. J Biol Chem. 2011 Jul;286(27):24159-69. https://doi.org/10.1074/ibc.M110.198085 
44. Burns E, Bachrach G, Shapira L, Nussbaum G. Cutting Edge: TLR2 is required for the innate response to Porphyromonas gingivalis: activation leads to bacterial persistence and TLR2 deficiency attenuates induced alveolar bone resorption. J Immunol. 2006 Dec;177(12):8296-300. https://doi.org/10.4049/jimmunol.177.12.8296

45. Myneni SR, Settem RP, Connell TD, Keegan AD, Gaffen SL, Sharma A. TLR2 signaling and Th2 responses drive Tannerella forsythia-induced periodontal bone loss. J Immunol. 2011 Jul;187(1):501-9. https://doi.org/10.4049/jimmunol.1100683

46. Park CH, Abramson ZR, Taba Junior, M, Jin Q, Chang J, Kreider JM, et al. Three-dimensional micro-computed tomographic imaging of alveolar bone in experimental bone loss or repair. J Periodontol. 2007 Feb;78(2):273-81. https://doi.org/10.1902/jop.2007.060252

47. Souza PP, Lerner UH. The role of cytokines in inflammatory bone loss. Immunol Invest. 2013;42(7):555-622. https://doi.org/10.3109/08820139.2013.822766 